\title{
Prevalence of attention deficit/hyperactivity disorder among adults in obesity treatment
} Jules R Altfas

Address: Behavioral Medical Center for Treatment and Research Portland, Oregon, USA

E-mail: jaltfas@earthlink.net

Published: I 3 September 2002

BMC Psychiatry 2002, 2:9
Received: 20 April 2002

Accepted: 13 September 2002

This article is available from: http://www.biomedcentral.com/I47I-244X/2/9

(C) 2002 Altfas; licensee BioMed Central Ltd. This article is published in Open Access: verbatim copying and redistribution of this article are permitted in all media for any purpose, provided this notice is preserved along with the article's original URL.

Keywords: ADHD, ADHD prevalence, obesity treatment, obesity treatment failure

\begin{abstract}
Background: Bariatric patients showing poor "focus" during treatment more often failed to lose weight or maintain reduced weight. Evaluation of these patients identified a number having attention deficit/hyperactivity disorder (ADHD), evidently a potent factor limiting successful weight control. After searches found no published reports describing comorbid ADHD and obesity, this report was conceived to begin exploring the prevalence and characteristics of these patients.
\end{abstract}

Method: Clinical records of 215 patients receiving obesity treatment during 2000 were reviewed. Data collected and analyzed included age, sex, beginning and ending body mass index (BMI), number of clinic visits, months of treatment, and diagnostic category (ADHD, some ADHD symptoms, nonADHD). DSM-IV criteria were used, except age of onset was modified to $<=12$ years.

Results: Whole sample ADHD prevalence was $27.4 \%$ (Cl:2I.I,32.9), but $42.6 \%$ (Cl: $36.3 \%$ to $48.9 \%)$ for $\mathrm{BMI}>=40$. Mean weight loss among obese patients with ADHD (OB+ADHD) was 2.6 BMI $\left(\mathrm{kg} / \mathrm{m}^{2}\right)$ vs. 4.0 for non-ADHD (NAD) $(\mathrm{p}<0.002)$. For BMI $>=40, \mathrm{OB}+\mathrm{ADHD}$ had BMI loss 2.9 vs. $7.0(N A D)(p<0.004)$. OB+ADHD had more clinic visits, with a trend toward longer treatment duration.

Conclusions: ADHD was highly prevalent among obese patients and highest in those with extreme obesity. Comorbid obesity and ADHD symptoms rendered treatment less successful compared to NAD counterparts. Reasons for the comorbidity are unknown, but may involve brain dopamine or insulin receptor activity. If replicated in further studies, these findings have important implications for treatment of severe and extreme obesity.

\section{Background}

Recent U.S. national surveys [1] show that in 1999, 18.9\% of Americans were frankly obese, a marked increase from $17.8 \%$ in 1998, underscoring the fact that over the last few decades, an emerging epidemic of obesity has become a major cause of preventable death [2] and disease [3]. Recognizing the effects of obesity on the nation's health, gov- ernments and industry have vigorously pursued the genetic, metabolic and environmental roots of obesity [47]. Despite the effort, it remains true that little is known about prevention of obesity and its treatment remains no less difficult or failure prone than it ever was [8-10]. 
Attention Deficit/Hyperactivity Disorder (ADHD) is also a common disorder, even if its prevalence is not precisely known. In children, the rate of occurrence has customarily been given as 3 to $5 \%$, but recent studies show the condition is present in $15 \%$ or more of school age populations $[11,12]$. Persistence of ADHD into adulthood has been shown to occur in 30 to $50 \%$ (or more) of childhood cases [13], depending on the criteria used [14]. It is clear that adults with a history of ADHD in childhood have greater difficulty functioning compared to their non-ADHD peers [15]. One example is the higher rate of substance use disorders in ADHD adults compared to the general population [16], such use often viewed as a kind of "selfmedication" of unpleasant emotions [16]. In obesity, similar patterns of eating (seeking immediate gratification, using food to reduce dysphoria) have been observed [17], though not previously linked to ADHD.

It is established that obesity has serious medical sequelae, and that both obesity and ADHD have psychiatric comorbidities [18-23], but surprisingly, searches found no existing literature describing comorbid obesity and ADHD (OB+ADHD). However, one study [24] reported a potentially relevant correlation between symptoms of conduct disorder (but not depression) during adolescence and obesity in early adulthood, attributed to common mechanisms underlying "impulsive aggression" and dysregulation of body weight. The role of impulsivity in this correlation is important, given that impulsive behavior is common in adolescents with ADHD, pointing to a connection between ADHD and development of obesity, an idea consistent with our clinical observation that impulsive eating behaviors are common in adult and adolescent $\mathrm{OB}+\mathrm{ADHD}$ patients.

With persistent effort some bariatric patients have been able to achieve and maintain a reduced level of body fat. In the bariatric clinic at Behavioral Medicine Center for Treatment and Research (BMedCTR) in Portland, Oregon, among the patients who failed, a subset was observed to have unusual difficulty adhering to diet and exercise plans, and as a result lost less fat mass than typically occurs. Diagnostic evaluation showed a substantial fraction of these patients had Attention Deficit/Hyperactivity Disorder (ADHD), a condition that was recognized in our clinical work as a risk factor for poor treatment outcome. Fortunately, ADHD patients often responded to pharmacological and behavior therapies, with results that included improved task persistence, decreased impulsivity and distractability, and for some, greater success with weight control efforts.

Cumulative bariatric clinic experience showed $\mathrm{OB}+\mathrm{AD}-$ HD was commonly encountered, and a potent contributor to obesity treatment failure. In this context it became clear that more information about OB+ADHD was needed and that wider exposure of this comorbidity would be valuable (and interesting) to clinicians treating obese patients. Consequently, this report was constructed to begin exploring the basic characteristics of this heretofore unrecognized population.

\section{Methods}

The primary working hypothesis was that the prevalence of ADHD among obese patients was higher than in the general adult population. In addition, it was anticipated that ADHD patients would have less weight loss, fewer visits and shorter duration of treatment than their nonADHD peers. Differences between groups were not expected to be widely divergent.

The method used to conduct a systematic examination of clinical data was a retrospective review of medical records of patients who had been treated for obesity at BMedCTR during the period, Jan 1, 2000 through Dec 31, 2000, and enrolled in treatment by Nov 30, 2000. The clinic's scheduling database referenced 215 unique individuals who were active patients during the study period.

Data relevant to demographic and clinical status was collected from medical records including age, sex, body mass index (BMI) at first and last visits, interval between first and last visits, number of visits, and diagnosis of ADHD entered in the record during the course of obesity treatment. This diagnosis was not determined retrospectively, although the diagnosis was confirmed to be supported by the written record of behavioral observations. The 215 records were were divided into 3 groups: patients without ADHD (NAD), those with ADHD symptoms or behaviors, but not meeting diagnostic criteria for ADHD (ADSx), and patients with ADHD (AD).

Diagnosis of ADHD was made by the author during the course of patients' obesity treatment, using semi-structured interviews over one or more visits. Structure was in accord with DSM-IV criteria, that is, a patient needed to have shown, or given substantial history of 6 or more inattentive behaviors to be considered as having ADHD. Patients who had fewer than 6 , but at least 3 inattentive symptoms were classified as having symptoms of ADHD but not diagnosed as having the disorder. None of the patients had as many as 6 hyperactive-impulsive symptoms. (Patients' inattentive and hyperactive/impulsive behaviors were not separately tabulated during records review.) At the time diagnoses had been made, a behavior was not considered a symptom of ADHD if occurring only in association with obesity treatment, for example, trouble adhering to diet or exercise plans. A significant level of impairment associated with symptoms was required for ADHD to be diagnosed. While many of the patients had 
current or past treatment for depression or anxiety, these conditions were required to be in remission or insufficiently prominent to obscure or account for ADHD behavior or impairment for the diagnosis of ADHD to be made.

The interview method is termed semi-structured because in a clinical setting the approach to each patient was necessarily individualized (at least to some degree). Within this constraint, information was gathered in a reasonably consistent manner, in that the same pieces of information were sought from each patient, the same questions asked of each, even if the order of inquiry varied, that is to say, the path through the "decision tree" reflected patients' differences.

During the period of treatment, and diagnosis, a single exception to DSM-IV ADHD diagnostic criteria was made regarding age of onset (nominally 7 years), for several reasons. Pragmatically, adult patients were often uncertain about the precise age symptoms began, though often able to identify a time in early childhood when symptoms were already occurring, e.g., "in the 2nd or 3rd grade", making it impossible to be certain if symptoms were present before age 7 . For middle-aged adults, third party confirmation of early events was seldom available, leaving the patient's recall as the only data source. Recent studies have shown that patient memory was consistent enough with other information to be useful for diagnostic purposes [25]. Patients' reports were likely to be accurate, but there were often "gaps" in memory of early experience, not inconsistent with ADHD in general, favoring an inference that they didn't remember their behavior rather than not having had the behavior. It was concluded that the risk of misdiagnosis by modifying the age of onset criterion was much lower than the risks of not diagnosing a condition for which treatment can make a great difference in life quality. In other words, for this population the risks of underdiagnosing ADHD were judged to be far more consequential than risks of overdiagnosing the disorder. Accordingly, during treatment, diagnosis of ADHD was made when all other DSM-IV criteria were met and symptoms were clearly evident by 12 years of age.

A similar point was made by Wender [26], who argued that availability of low-risk treatments for debilitating conditions warrants clinicians using less specific criteria to avoid excluding patients who may benefit. A different argument was made by Barkley and Biederman [27], that requiring symptoms to have been present by a single, specific point in early childhood in order to diagnose ADHD is not rational, that is, ADHD is better conceptualized as a disorder arising in childhood generally.
None of the ADHD group had a level of hyperactivity-impulsivity meeting DSM-IV criteria, therefore all were classifiable as having Inattentive Type of ADHD.

Data were tested using Unix-based tools including xmstat and xlispstat. Significance was set at $\alpha=0.05$. Analysis of variance was applied to means of age, starting BMI, difference between starting and ending BMI, number of visits and length of treatment. Chi-square test was used to determine significance of differences among patient groups and BMI categories. NIH classification [3] of BMI was used, defining Obesity III (Extreme Obesity) as BMI >= 40, Obesity classes I and II (Obesity) as BMI 30 to 39.9, and Overweight as BMI 25 to 29.9.

\section{Results}

Results are summarized in Table 1. While the patients in the sample were predominantly female, there was no significant difference in age ( $\mathrm{F}=0.52, \mathrm{df}=2,212, \mathrm{p}=\mathrm{NS})$ or gender distribution (chi-square $=2.35, \mathrm{df}=2, \mathrm{p}=0.31$ ) among patient groups. Mean Starting BMI - Ending BMI was 3.32 for males, 3.02 for females, but the difference was not significant (unpaired t-test, $\mathrm{t}=1.73, \mathrm{df}=21,192$, 213, $\mathrm{p}=0.09$ ).

Subjects were characterized by a variable level of obesity, divided into one of three obesity classes (overweight:Ov, moderate to severe obesity:I-II, and extreme obesity:III), and a range of symptoms (AD, ADSx, or NAD). These classifications were organized into a $3 \times 3$ array which was suitable for determining prevalence of ADHD in whole sample and looking at the differences in ADHD prevalence among the classes of obesity.

The whole sample of 215 obese patients, partitioned by ADHD group, contains 59, or $27.4 \%$ (95\% CI:21.1\% to $32.9 \%$ ) with $\mathrm{AD}, 72$ or $33.5 \%$ (CI: $27.2 \%$ to $39.8 \%$ ) were ADSx, and 84 or $39.1 \%$ (CI:32.6\% to $45.6 \%$ ) were NAD. Chi-square test of patient groups (AD, ADSx, NAD) vs. obesity classes (III, I-II, Ov) showed that differences in the $3 \times 3$ table were significant (chi-square $=11.23, \mathrm{df}=4, \mathrm{p}$ $<0.025)$. The proportion of patients having ADHD in obesity class III (Ob-III) was significantly greater than for Obesity I-II (Ob-I/II) and Ov (chi-square $=9.86, \mathrm{df}=1, \mathrm{p}$ $=0.002$ ). However, the proportion of $\mathrm{AD}$ in the Ov class did not significantly differ from Ob-I/II and Ob-III (chisquare $=2.60, \mathrm{df}=1, \mathrm{p}=0.11)$.

There were 26 patients with ADHD and Ob-III, which is $42.6 \%$ (CI:36.3\% to $48.9 \%$ ) of all 61 Ob-III patients in the sample. Similarly, there were $23 \mathrm{AD}$ with Ob-I/II (22.8\% [CI:14.6\% to $31.0 \%$ ] of $101 \mathrm{Ob}-\mathrm{I} / \mathrm{II})$, and $10 \mathrm{AD}$ in Ov (18.9\% [CI:8.4\% to $29.4 \%$ ] of $53 \mathrm{Ov})$, though the value for $\mathrm{AD} / \mathrm{Ov}$ was not statistically distinct from $\mathrm{AD}$ in other obesity classes. 
Table I:

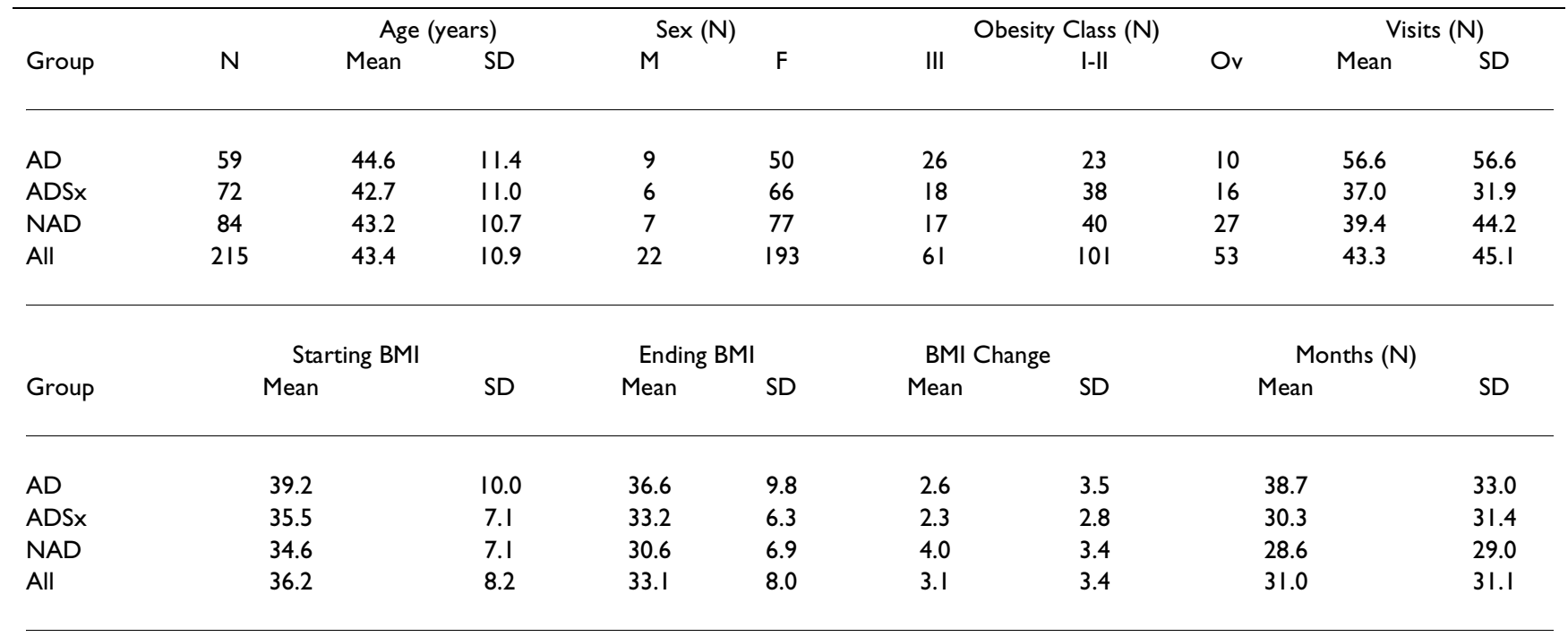

Group: $A D=$ diagnosed with $A D H D ; A D S x=$ behaviors consistent with $A D H D$ criteria, but insufficient to allow diagnosis; $N A D=$ few or no symptoms consistent with ADHD. Obesity class: III (Extreme Obesity) = BMI >= 40; I-II (Obesity) = BMI 30 to 39.9; Ov (Overweight) $=$ BMI < 30. BMI Change: Ending BMI - Starting BMI. Months: Total number of months between first and last visits, inclusive.

Analysis of variance of patients' BMI at the start of treatment showed a significant difference among the group means $(\mathrm{F}=5.86, \mathrm{df}=2,212, \mathrm{p}=0.003)$, with $\mathrm{AD}$ having a higher BMI (39.2) than ADSx (35.5) and NAD (34.6). Further analysis with the Fisher multiple comparison test found AD differed from ADSx and NAD, but ADSx and NAD were not significantly different (Fisher, AD-ADSx: $\mathrm{p}$ $=0.001$, AD-NAD: $\mathrm{p}=0.01$, ADSx-NAD: $\mathrm{p}=0.49)$.

Body weight loss was calculated as Starting BMI - Ending BMI. NAD achieved nearly twice the BMI loss as AD and ADSx, at means of $4.0,2.6$ and 2.3 respectively $(F=6.25$, $\mathrm{df}=2,212, \mathrm{p}=0.002)$. NAD was distinct from $\mathrm{AD}$ and ADSx (Fisher, NAD-AD: $\mathrm{p}<0.009$, NAD-ADSx: $\mathrm{p}<.001$, AD-ADSx: $p=0.666)$. As percent change from Starting BMI, mean loss was $11.2 \%, 6.5 \%$ and $6.3 \%$ respectively ( $\mathrm{F}$ $=8.40, \mathrm{df}=2,212, \mathrm{p}=<0.01)$, with NAD being significantly different from $A D$ and ADSx which did not differ from each other (Fisher, NAD-AD: p < 0.001, NAD-ADSx: $\mathrm{p}<$ .001$, AD-ADSx: $\mathrm{p}=0.93)$.

The subgroup of patients having Obesity III showed a larger difference in mean BMI change, that is, BMI loss by ADHD status for members of this subgroup was: NAD 7.0 (SD 4.0), AD 2.9 (SD 4.5) and ADSx 3.4 (SD 2.8) $(\mathrm{F}=$ 6.09 , $\mathrm{df}=2,58, \mathrm{p}=0.004)$. The weight loss for NAD was again different from Obesity III patients who were AD or ADSx, but AD and ADSx were not significantly different (Fisher, NAD-AD: p < 0.001, NAD-ADSx: p < 0.01, ADADSx: $\mathrm{p}<0.657)$. The Obesity III AD and NAD were ana- lyzed by the non-parametric approximate randomization test (AR test) which also showed a significant difference between the two groups ( $\mathrm{p}=0.003$ (CI:0.0019 to 0.0041), 10000 randomizations).

Among the whole sample of obese patients, mean number of visits was greater in $\mathrm{AD}(\mathrm{F}=3.69, \mathrm{df}=2,212, \mathrm{p}$ $=0.027$ ) with $\mathrm{AD}$ differing significantly from $\mathrm{NAD}$ and ADSx (Fisher, AD-NAD: $p=0.02$, AD-ADSx: $p=0.01$, NAD-ADSx: $p=0.73)$. AR test applied to the number of visits of $A D$ and NAD revealed a marginally significant difference ( $\mathrm{p}=0.040$ (CI:0.036 to 0.048), 4000 randomizations). The number of months in treatment was not significantly different among the patient groups $(\mathrm{F}=2.03$, $\mathrm{df}=2,212, \mathrm{p}=0.13)$, though there appeared to be a trend toward alonger duration of treatment in $\mathrm{AD}$. AR test results for AD vs. NAD showed a nearly significant difference, remaining better described as trend toward a difference ( $\mathrm{p}=0.054$ (CI:0.050 to 0.058), 12000 randomizations).

\section{Discussion}

The most important results are the prevalence of ADHD of $27.4 \%$ in the sample, and the surprisingly strong association between ADHD and Obesity III. Nearly half, 42.6\%, of patients with Obesity III had ADHD, that is, the $\mathrm{OB}+\mathrm{ADHD}$ population was concentrated in the obesity class having the highest mortality and morbidity risks, and greatest need for effective treatment. 
Moreover, at all levels of obesity patients with ADHD symptoms were less successful at losing weight than nonADHD peers. Compared to NAD, AD had a significantly higher starting BMI (39.6 vs. 34.2), yet lost less weight $\left(2.6\right.$ vs. $\left.4.0 \mathrm{~kg} / \mathrm{m}^{2}\right)$. Greater contrast is found in Obesity III, with NAD in that class achieving more than twice the weight loss of $\mathrm{AD}$ (7.0 vs. $2.9 \mathrm{~kg} / \mathrm{m}^{2}$ ), while mean weight loss for ADSx did not differ significantly from AD (2.3 vs. $2.6 \mathrm{~kg} / \mathrm{m}^{2}$ ), implying that the presence of even "subthreshhold" ADHD symptoms reduces the effectiveness of obesity treatment. In other words, in OB+ADHD, treatment outcome has stronger association with symptoms of ADHD than level of obesity. Effect size of ADHD for the whole sample was only about 0.2 , but in Obesity III patients, effect size was about 0.5 , comparable, for example, to the moderate effect size of SSRI drugs on panic symptoms [28].

Impersistence was not the cause of worse results for $\mathrm{AD}$, who attended more visits than NAD (56.0 vs. 39.4 mean total visits), over a longer span of time. ADSx was no more successful than $\mathrm{AD}$, but had fewer visits, comparable to $\mathrm{NAD}$, in this respect, ADSx showing characteristics intermediate between $\mathrm{AD}$ and NAD. The result is AD, ADSx and NAD having similar rates of clinic visits (AD had 1.5 visits/month, ADSx 1.2 and NAD 1.4), while NAD had the highest rate of BMI decrease (NAD lost $0.14 \mathrm{BMI} /$ month, ADSx 0.075 and AD 0.067). However, these statistics have limited utility, given the large variance in number of visits and months of treatment. The "slow" aspect of task performance in ADHD has been previously reported [29], and could be described as a kind of "inefficiency", that is, taking more time to accomplish less.

The reasons for a strong association between ADHD and obesity (particularly extreme obesity) are unknown, but there are a number of reported findings that appear to be relevant and certainly interesting. For one, evidence exists that variations of dopamine receptor (DR) genes affect both conditions. In obesity, DRD2 and DRD4 [30,31] genes, and in ADHD, the DRD4 [32,33] gene, have been implicated in the transmission of, or predisposition to, the disorders, raising the possibility that similar, overlapping or shared DR functioning (or dysfunction) in these disorders is related to their CO-co-occurrence.

DRD2 and a range of dopamine and other genes have been associated with a "reward deficiency syndrome" [34] in which insufficient dopamine-mediated "natural" reward leads to use of "unnatural" rewards, such as substances, gambling, risk taking and inappropriate eating. This syndrome is associated with obesity [34], and common in ADHD [22]. The DRD4 gene has been associated with "novelty seeking" traits, said to be greater in substance abusers [30], and individuals with both DRD2 and
DRD4 genetic variations may be especially prone to multiple difficulties (e.g., having both ADHD and "reward deficiency syndrome") [30], further suggesting obesity and ADHD could share neurobiological attributes.

A recent study showed the availability of striatal DRD2 receptors was decreased as a function of increasing BMI [35], supporting the idea that reward-seeking behavior plays a role in the onset or continuation of obesity. In other studies, administration of D2 agonists resulted in decreases in hyperinsulinemia associated with obesity [36], and it is known that the brain is richly supplied with insulin receptors, including the cortex and striatal areas [37], suggesting an intriguing link between insulin resistance, characteristic of obesity, and dopamine-mediated psychiatric symptoms, including ADHD. No doubt, this hypothesis and many far more refined hypotheses will be studied in coming years and will elucidate the complex neurophysiological connections hinted at by the above.

The $27.4 \%$ prevalence of ADHD in obese patients is considerably higher than found in the general adult population, reported as $4.7 \%$ by Murphy and Barkley [38]. Across studies of other specific populations, prevalence of ADHD or ADHD symptoms was also greater than in general, for example, cocaine abusers $12 \%$ [39], anxiety disorders $16 \%$ [40], panic disorder 22\% [41], and substance abusers 25\% [42]. Considering the differing methods and populations, the reported prevalences are difficult to compare, yet are fairly consistent with one another for the most part. The prevalence of $\mathrm{OB}+\mathrm{ADHD}$ in this report is plausibly within the range of these studies.

The uniformity of the Inattentive subtype of ADHD in this adult population was not unusual or unexpected, considering the well-known attenuation of hyperactive and impulsive symptoms observed as children with ADHD grow into adolescence and adulthood, compared to the much stronger retention of inattentive symptoms [14]. This is not to say that ADHD adults don't behave impulsively, simply that with maturation, continuing hyperactive/impulsive (H/I) behaviors are usually expressed in less obvious ways than among their school-age counterparts. That is, while ADHD adults frequently have impairing $\mathrm{H} / \mathrm{I}$ symptoms, the number and types of these behaviors seldom meet DSM-IV diagnostic criteria for the H/I or Combined subtype of ADHD. DSM-IV ADHD subtyping, strictly applied, is likely to have limited correlation to neurobiological processes (assuming processes reflect impulsivity or disinhibition), since the level of symptomatic behavior required for diagnosing DSM-IV H/I or Combined subtypes is higher than nearly all ADHD adults will display, even if substantial $\mathrm{H} / \mathrm{I}$ behavior is evident. 
Another factor is that girls, compared to boys, have lower rates of H/I symptoms, which is associated with lower likelihood of being diagnosed in childhood, but if diagnosed, girls more frequently have the Inattentive subtype [12]. It would be expected that this difference would persist into adulthood, augmenting the likelihood that Inattentive symptoms would predominate the clinical presentation. In a sample in which most patients are female and middle-aged, predominance of the Inattentive subtype is predictable.

Inevitably, there are numerous caveats and limitations that apply to this preliminary work. For one, results reflect the origin of data in clinical practice - hardly ideal from a research perspective. Treatment settings may favor a higher case-finding rate because of the opportunity to observe and assess behavior is greater than the methods of prospective research designs. For example, ADHD research instruments have a sensitivity of $70-90 \%[43,44]$, and would likely identify fewer cases of ADHD than the "gold standard" of careful clinical assessment, expected to find most cases. For this report, diagnosis had been made primarily by one interviewer, which could favor consistency, but also leads to potential biases that skew results. In addition, the modification of age of onset criterion for ADHD may increase difficulty of comparing present results to those of studies using the unmodified criterion. Clearly, for the purpose of comparing prevalence among diverse populations, a prospective design is strongly advantageous, but likely not congruent with the goals of clinical practice.

Bias could also be introduced by patient factors, such as comorbid conditions producing symptoms which might not be easily separable from those found in ADHD, and erroneously diagnosed as ADHD. Several disorders common in obese patients fit into this category, e.g., obstructive sleep apnea, depression, and anxiety disorders. While the differential characteristics of these conditions, e.g., relative duration, pervasiveness and continuity of symptoms can help distinguish one from another, the nature and interactions of these comorbidities are not particularly welldelineated. While careful clinical practice requires effort to avoid diagnosing ADHD if symptoms are not sufficiently distinct from those of confounding disorders, reducing error requires further research into the effects of comorbidities intercurrent with ADHD.

Another form of bias originates in patients' predisposition to endorse symptoms because of dysphoria, negative affectivity, or readiness to attribute distress to some preferred, rather than actual, source when queried by the interviewer. For the OB+ADHD population, the idea is that some patients may have had a preference for endorsing ADHD symptoms, instead of accepting more accurate explanations for distress or lack of obesity treatment progress, e.g., failure to lose weight while being unwilling to exercise. ("I can't lose weight because I just get so distracted.")

Some forms of endorsement bias are readily seen in medical practice, for example, patients who would rather talk about somatic events than discuss their anxieties or depressed mood. Implications for the OB+ADHD population are hard to assess, since this form of bias and its effects on research of ADHD prevalence have not received comparable study, nor are there reports of the frequency of encountering this bias in clinical work with adult ADHD patients. Moreover, no special measures were taken to reduce or account for such biases during the course of diagnosing patients in the present sample, rendering it quite difficult to estimate how much and what kind of effect biases have had on the above reported prevalences of $\mathrm{OB}+\mathrm{ADHD}$. At this point, it remains an open question, suggesting additional reasons for cautious interpretation of the results given in this report.

The demographic characteristics of the sample population are worth a few comments. Notably, about $90 \%$ of the patients were women, which obviously does not reflect the general population, but may not be surprising in this context because more women than men are concerned about weight gain, and are more likely to seek medical care than male contemporaries. The patients as a group were also distinctly middle-aged, no doubt reflecting the fact that older individuals are more likely to be able to afford noninsured medical care (obesity treatment isn't covered under most policies), and the time to devote to their own needs.

Some effects of demographic factors on diagnosis of ADHD were discussed above. Gender and age differences (e.g., younger patients or higher male to female ratio) could conceivably affect the range and intesity of ADHD symptoms that are observed, prevalence findings, and individual as well as aggregate response to obesity treatment.

In addition, generalizability of conclusions based on the data in this report are limited by a modest sample size, and uncertainty that the bariatric patients in the sample were truly representative of the general obese population. Results could be misleading, for example, if the sample had a disproportion of individuals with serious medical or psychiatric problems, higher weight or greater social skill deficits, even if the sample is construed to be typical of those seen in similar practices. 


\section{Conclusion}

This report is explicitly exploratory, and its findings need to be replicated in larger and more systematic studies. Nonetheless, these findings are already quite interesting and could have implications for the understanding of the etiology of obesity as well as the treatment of obesity. The nature of the connections, to the extent that they exist, between attention and obesity is of course not at all clear, but the results may point to forms of attentional components and impulsivity playing a role in the onset or continuation of obesity, or that attentional mechanisms are linked in some way to metabolic and energy storage regulation.

Implications for clinical practice may be of more immediate consequence. Treatment of obesity has been marginally effective at best, particularly for extreme obesity. If an attentional disorder is present, conceivably its treatment could improve obesity treatment outcome, which makes awareness of the ADHD-obesity comorbidity pragmatically important. It has been shown that reduction of body weight as small as 5\% substantially reduces the morbidity and mortality risks of obesity, so even if recognizing and treating ADHD is only a modest contributor to reducing body fat mass, it is worthwhile on that grounds alone. Moreover, the impairment of ADHD is an intrinsic reason to diagnose and treat the condition, because even if comorbid obesity were not changed, normalizing brain function in ADHD sufferers more often than not provides substantial benefit and improved quality of life.

The apparent association of $\mathrm{OB}+\mathrm{ADHD}$, relatively poor obesity treatment outcome and high prevalence of $\mathrm{OB}+\mathrm{ADHD}(27.4 \%)$, especially in the extremely obese $(42.6 \%)$, argue that comorbid ADHD increases the health risks of obesity, and that extreme obesity, itself a stressful condition, adds burden to the profound impairments common in ADHD. The chance that more knowledge could lead to reduction of suffering, disability and economic cost offers compelling reasons for further investigation of this subject. Inclusion of more diverse and nonclinical populations of obese and extremely obese individuals, and using research designs that better account for rater and subject biases, inter-rater reliability, and diagnostic methodology, will likely give more definitive answers to this report's questions and implications.

\section{Competing interests}

None declared.

\section{Authors' contributions}

The author (1) JRA developed and wrote this report.

\section{References}

I. Mokdad AH, Serdula MK, Dietz WH, Bowman BA, Marks JS, Koplan JP: The continuing epidemic of obesity in the United States. JAMA 2000, 284: I65I-2

2. McGinnis JM, Foege WH: Actual causes of death in the United States: JAMA 1993, 270:2207-12

3. National Institutes of Health: clinical guidelines on the identification, evaluation and treatment of overweight and obesity in adults - the evidence report. Obes Res 1998, 6(Suppl 2):71-79S

4. Perusse L, Chagnon YC, Weisnagel SJ, et al: The human obesity gene map: the 2000 update. Obes Res 2001, 9:135-169

5. Reaven GM: Banting lecture: role of insulin resistance in human disease. Diabetes 1988, 37:1595-1607

6. Bruning JC, Gautum D, Burks DF, et al: Role of brain insulin receptors in control of body weight and reproduction. Science 2000 , 289:2। 22-5

7. Gibbs WW: Gaining on fat. Sci Am 1996, 275:88-94

8. National Institutes of Health Technology Assessment Conference: Methods for voluntary weight loss and control. Office of Medical Applications of Research, National Institutes of Health, Bethesda, MD 1992

9. Stunkard SE: The current status of treatment of obesity in adults. In: Eating and its disorders (Edited by: Stunkard AJ, Stellar E) New York, Raven Press 1984

10. Wilson GT: Behavioral treatment of obesity: thirty years and counting. Adv Behav Res Ther 1994, 16:31-75

II. Nolan EE, Gadow KD, Sprafkin J: Teacher reports of DSM-IV ADHD, ODD and CD symptoms in schoolchildren. J Am Acad Child Adolesc Psychiatry 200I, 40:24I-249

12. Wolraich ML, Hannah JN, Baumgaertel A, Feuer ID: Examination of DSM-IV criteria for attention deficit/hyperactivity disorder in a county-wide sample. J Dev Behav Pediatr 1998, 19:162-168

13. Searight HR, Burke JM, Rottnek F: Adult ADHD: evaluation and treatment in family medicine. Am Fam Physician 2000, 62:207786

14. Biederman J, Mick E, Faraone SV: Age-dependent decline of symptoms of attention deficity/hyperactivity disorder: impact of remission definition and symptom type. Am J Psychiatry 2000, 157:816-818

15. Faraone SV, Biederman J, Spencer T, et al: Attention-deficit/hyperactivity disorder in adults: an overview. Biol Psychiatry 2000, 48:9-20

16. Levin FR, Evans SM: Diagnostic and treatment issues in comorbid substance abuse and adult attention-deficit hyperactivity disorder. Psychiatric Ann 200 I, 3 I:303-312

17. Parham PS: Compulsive eating: applying a medical addiction model. In: Obesity: new directions in assessment and management. (Edited by: Vanltallie TB, Simopoulos AP) Philadelphia, The Charles Press 1995

18. Black DW, Goldstein RB, Mason EE: Prevalence of mental disorder in $\mathbf{8 8}$ morbidly obese bariatric clinic patients. Am J Psychiatry 1992, I 49:227-234

19. Blum K, Braverman ER, Wood RC, et al: Increased prevalence of the Taq I A I allele of the dopamine receptor gene (DRD2) in obesity with comorbid substances use disorder: a preliminary report. Pharmacogenetics 1996, 6:297-305

20. Cugini P, Cilli M, Salandri A, et al: Anxiety, depression, and body composition: III. Their relationships in obese patients. Eat Weight Disord 1999, 4:115-120

21. Jensen PS, Hinshaw SP, Kraener HC, et al: ADHD comorbidity findings from the MTA study: comparing comorbid subgroups. J Am Acad Child Adolesc Psychiatry 2001, 40: I47-I58

22. Murphy K, Barkley RA: Attention deficit hyperactivity disorder adults: comorbidities and adaptive impairments. Compr Psychiatry 1996, 37:393-40 I

23. McCann BS, Roy-Byrne P: Attention-deficit/hyperactivity disorder and learning disabilities in adults. Semin Clin Neuropsychiatry 2000, 5: $191-197$

24. Pine DS, Cohen P, Brook J, Coplan JD: Psychiatric symptoms in adolescence as predictors of obesity in early adulthood: a longitudinal study. Am J Public Health 1997, 87: 1303-1310

25. Murphy $P$, Schachar R: Use of self-ratings in the assessment of symptoms of attention deficit hyperactivity disorder in adults. Am J Psychiatry 2000, I 57: I I56-I I59

26. Wender PH: Attention-deficit hyperactivity disorder in adults. New York, Oxford University Press. 1995, 45-47 
27. Barkley RA, Biederman J: Toward a broader definition of the age-of-onset criterion for attention-deficit hyperactivity disorder. J Am Acad Child Adolesc Psychiatry 1997, 36:1204-10

28. Otto MW, Tuby KS, Gould RA, McLean RY, Pollack MH: An effectsize analysis ofthe relative efficacy and tolerability of serotonin selective reuptake inhibitors for panic disorder. Am J Psychiatry 200I, I 58:1989-1992

29. Swanson J, Oosterlaan J, Murias M, et al: Attention deficit/ hyperactivity disorder children with a 7-repeat allele of the dopamine receptor D4 gene have extreme behavior but normal performance on critical neurospychological tests of attention. Proc Natl Acad Sci 2000, 97:4754-4759

30. Noble EP: The DRD2 gene in psychiatric and neurological disorders and its phenotypes. Pharmacogenomics 2000, I:309-33

31. Poston WS 2nd, Ericsson M, Linder J, et al: D4 dopamine receptor gene exon III polymorphism and obesity risk. Eat Weight Disord 1998, 3:7|-77

32. Sunohara GA, Roberts $W$, Malone $M$, et al: Linkage of the dopamine D4 receptor gene and attention-deficit/hyperactivity disorder. I Am Acad Child Adolesc Psychiatry 2000, 39:I537-42

33. Muglia P, Jain U, Macciardi F, Kennedy JL: Adult attention deficit hyperactivity disorder and the dopamine D4 receptor. Am J Med Genet 2000, 96:273-277

34. Comings DE, Blum K: Reward deficiency syndrome: genetic aspects of behavioral disorders. Prog Brain Res 2000, I 26:325-34 I

35. Wang G], Volkow ND, Logan J, et al: Brain dopamine and obesity. Lancet 200I, 357:354-357

36. Cincotta $\mathrm{AH}$, Meier $\mathrm{AH}$, Cincotta Jr: Bromocriptine improves glycaemic control and serum lipid profile in obese Type 2 diabetic subjects: a new approach in the treatment of diabetes. Expert Opin Investig Drugs 1999, 8:1683-1707

37. Schulingkamp RJ, Pagano TC, Hung D, Raffa RB: Insulin receptors and insulin action in the brain: review and clinical implications. Neurosci Biobehav Rev 2000, 24:855-872

38. Murphy K, Barkley RA: Prevalence of DSM-IV symptoms of attention deficit hyperactivity disorder in adult licensed drivers. I Attention Disorders 1996, I:|46-16 |

39. Levin FR, Evans SM, Kleber HD: Prevalence of adult attentiondeficit hyperactivity disorder among cocaine abusers seeking treatment. Drug Alcohol Depend 1998, 52:15-25

40. Mancini C, Van Ameringen M, Oakman JM, Figueiredo D: Childhood attention deficit/hyperactivity disorder in adults with anxiety disorders. Psychol Med 1999, 29:5। 5-525

41. Fones CS, Pollack MH, Susswein L, Otto M: History of childhood attention deficit hyperactivity disorder (ADHD) features among adults with panic disorder. J Affect Disord 2000, 58:99-I 06

42. Schubiner H, Tzelepis A, Milberger S, et al: Prevalence of attention-deficit/hyperactivity disorder and conduct disorder among substance abusers. J Clin Psychiatry 2000, 6 I:244-25 I

43. Weiler MD, Bellinger DK, Simmons EK, et al: Reliability and validity of a DSM-IV based ADHD screener. Neuropsychol Dev Cogn Sect C Child Neuropsychol 2000, 6:3-23

44. Schreiber HE, Javorsky DJ, Robinson JE, Stern RA: Rey-Osterrieth Complex Figure performance in adults with attention deficit hyperactivity disorder: a validation study of the Boston Qualitative Scoring System. Clin Neuropsychol 1999, I 3:509-520

\section{Pre-publication history}

The pre-publication history for this paper can be accessed here:

http://www.biomedcentral.com/1471-244X/2/9/prepub

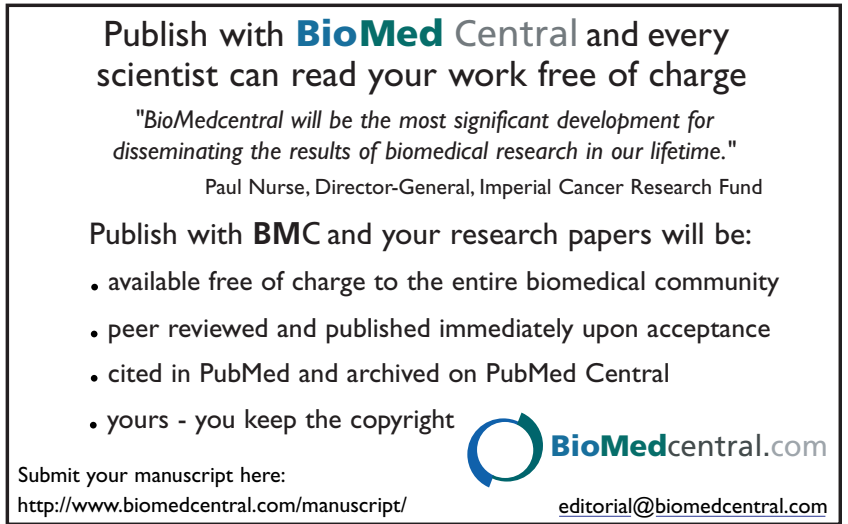

